\title{
A cross sectional study to evaluate the operational skills of asha in randomly selected districts of indore $\&$ ujjain division
}

\author{
Goswami V.P. ${ }^{1}{ }^{*}$, Rai S. ${ }^{2}$, Dixit S. ${ }^{3}$, Mahawar P. ${ }^{4}$, Jain C. ${ }^{\mathbf{5}}$ \\ DOI: https://doi.org/10.17511/ijphr.2016.i2.01
}

1* Goswami V.P., Medical Officer, Government of Madhya Pradesh, Indore, Madhya Pradesh, India.

2 Sailesh Rai, Resident, Department of Community Medicine, M.G.M. Medical College, Indore, Madhya Pradesh, India.

3 Sanjay Dixit, Professor \& Head, Department of Community Medicine, M.GM Medical College, Indore, Madhya Pradesh, India.

${ }^{4}$ Priyanka Mahawar, Assistant Professor, Department of Community Medicine, M.GM Medical College, Indore, Madhya Pradesh, India.

5 Chakresh Jain, Resident, Department of Community Medicine, M.G.M. Medical College, Indore, Madhya Pradesh, India.

Background: ASHA have been introduced to fill the void created by overburdening of work of anganwadi workers, who employed under the ICDS, are engaged in organizing supplementary programs. The key tasks for the next phase of the NRHM are to equip the ASHA with additional skills to enable an active role for her in not just Reproductive and Child Health but also to undertake action for prevention. Community level cares for Non-communicable Diseases should be encouraged. Methods: A cross sectional study was conducted in randomly selected two districts each from Indore and Ujjain divisions of the state of Madhya Pradesh. 100 ASHAs (Accredited Social Health Activists) and 50 ANMs (Auxiliary Nurse Midwife) were the study population. Data was collected with the help of semi structured questionnaire and Performa for skill evaluation. Results: Hand washing was performed by $93 \%$ participants, $67 \%$ were table to take proper temperature recording, $57 \%$ were able to weight newborns, $87 \%$ were able to apply eye ointment, $53 \%$ were able to cover the newborn with the blanket and $38 \%$ were able to keep the newborn in warm bag. Mean skill score of Indore and Ujjain Divisions came to be nearly equal and had no significant difference (Unpaired $t$ test, $p$ > 0.05). Conclusion: Quality of training had a positive effect on knowledge, skills and activities undertaken by ASHAs. The work done by ASHAs was mostly focused on incentives; they were giving priorities to activities with good incentives over other activities.

Keywords: ASHA, Accredited Social Health Activist, Operational Skills, NRHM, ICDS

Corresponding Author

Goswami V.P., Medical Officer, Government of Madhya Pradesh, Indore, Madhya Pradesh, India.

Email: drvpgoswami@gmail.com
How to Cite this Article

Goswami VP, Rai S, Dixit S, Mahawar P, Jain C. A cross sectional study to evaluate the operational skills of asha in randomly selected districts of indore $\&$ ujjain division. Public Health Rev Int J Public Health Res. $2016 ; 3(2): 48-53$.

Available From

https://publichealth.medresearch.in/index.php/ijphr/ article/view/30
To Browse

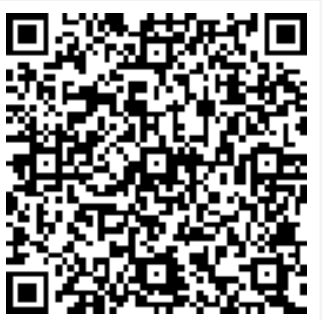

Manuscript Received 2015-03-16

Conflict of Interest No
Review Round 1 2015-03-25

Funding Nil

$\begin{gathered}\text { Review Round } 2 \\ \text { 2015-04-05 }\end{gathered}$
Ethical Approval
Yes

Review Round 2

Yes
Review Round 3

Accepted 2015-04-14

Plagiarism X-checker $6 \%$ () 2016 by Goswami V.P., Sailesh Rai, Sanjay Dixit, Priyanka Mahawar, Chakresh Jain and Published by Siddharth Health
Research and Social Welfare Society. This is an Open Access article licensed under a Creative Commons Attribution 4.0 International License https://creativecommons.org/licenses/by/4.0/ unported [CC BY 4.0] 


\section{Introduction}

In 2005 with the launch of the National Rural Health Mission, country committed itself to a vision of universal access to health, with a strong focus on community engagement to ensure people's participation in health and to enable action on the social determinants of health. The key instruments were the ASHA and the Village Health, Sanitation and Nutrition Committees. There was little experience with implementing large scale community health worker programmes. Despite this, most states have overcome steep learning curves to lay the foundations for a viable ASHA programme [1-3].

ASHA have been introduced to fill the void created by overburdening of work of anganwadi workers, who employed under the ICDS, are engaged in organizing supplementary programs. According to the guidelines, the purview of ASHA's work includes creating awareness about basic nutrition, sanitation, counseling women on birth preparedness, importance of safe delivery, escorting pregnant women and children requiring treatment, providing primary medical care for minor ailments, among others.

The key tasks for the next phase of the NRHM are to equip the ASHA with additional skills to enable an active role for her in not just Reproductive and Child Health but also to undertake action for prevention and community level care for Non-communicable Diseases. This can be achieved through high quality training and field support and mentoring, through strengthening the VHSNC as an institution for community action and enable both, the ASHA and VHSNC to function in a coordinated manner to
Ensure achievement of positive health outcomes at the community level [2].

The present study targets to evaluate the functional dynamics of ASHAs with AWW, and ANM and to study the indicators of their good performance by assessing improvement in job performance as well as by adequacy of incentive. The results of the study can be used to suggest recommendation for training \& enhancement of functional efficacy of ASHAs.

\section{Material and Methods}

A cross sectional study was conducted in randomly selected two districts each from Indore and Ujjain divisions namely Indore, Jhabua and Dewas, Neemuch respectively of the state of Madhya Pradesh over the period of 24 Months (January 2013 to December 2014). 100 ASHAs (Accredited Social Health Activists) and 50 ANMs (Auxiliary Nurse Midwife) were the study population.

Data was collected with the help of Interview of ASHAs based on the pre tested semi structured questionnaire regarding activities undertaken by ASHA and their incentives and Observation of skills based on the Performa for skill evaluation as used for practical assessment after the training and observation of activities performed. The data collected were analyzed through percentages and frequencies in which the data were presented in table formats, pie charts and histograms which were obtained using Excel and using SPSS (Statistical Package for Social Science) version 20.

\section{Results}

The following results were obtained on observation:

Table 1: Socio demographic profile of ASHAs selected for evaluation of Skills, change in behaviour and to study the incentives related issues:

\begin{tabular}{|l|l|l|l|l|l|l|}
\hline S. No. & \multicolumn{1}{|c|}{ Characteristics of ASHAs } & \multicolumn{1}{|c|}{ Indore } & \multicolumn{1}{|c|}{ Jhabua } & \multicolumn{1}{|c|}{ Dewas } & \multicolumn{1}{|c|}{ Neemuch } & \multicolumn{1}{c|}{ Total } \\
\hline 1. & No. of ASHAs/USHAs Surveyed & 28 & 24 & 32 & 16 & 100 \\
\hline 2. & Average Age of ASHAs /USHAs (in years) & 27 & 26 & 28 & 25 & 26.50 \\
\hline 3. & $\%$ of Married ASHAs/USHAs & $25(89.28 \%)$ & $24(100 \%)$ & $29(90.62 \%)$ & $15(93.75 \%)$ & $133(83.2 \%)$ \\
\hline 4. & $\%$ ASHAs /USHAs Educated below 8th class & $28 \%(76)$ & $35 \%(84)$ & $24 \%(74)$ & $25 \%(40)$ & $28 \%(274)$ \\
\hline 5. & Average No. of Years of Service & 05.60 & 3.5 & 04.03 & 05.00 & 4.53 \\
\hline
\end{tabular}

Among the ASHAs included in the study almost $93 \%$ were married and remaining $7 \%$ were unmarried/ widowed. The mean age of ASHAs was 26.5 years with a range of 17 to 58 years in both the divisions.
About 3/4th (72\%) of ASHAs had eligible qualification of class 8 th and above while the rest (28\%) were without eligible qualification, selected as ASHA due to unavailability of qualified candidates. 
Table 2: Number of ASHAs able to perform skills correctly (mean score obtained against max. score 10 for each skill)

\begin{tabular}{|l|l|l|l|l|l|}
\hline S. No. & \multicolumn{1}{|c|}{ Skills } & Maximum score & (Competent) Mean score $>\mathbf{7}$ & (Incompetent) Mean score $<7$ & \% Able to perform skill \\
\hline 1. & Hand washing & 10 & 93 & 7 & $93.00 \%$ \\
\hline 2. & Temperature recording & 10 & 67 & 33 & $67.00 \%$ \\
\hline 3. & Weighing newborn & 10 & 57 & 43 & $57.00 \%$ \\
\hline 4. & Application of eye ointment & 10 & 87 & 13 & $87.00 \%$ \\
\hline 5. & Covering newborn with blanket & 10 & 53 & 47 & $53.00 \%$ \\
\hline 6. & Keeping newborn in warm bag & 10 & 38 & 62 & $38.00 \%$ \\
\hline
\end{tabular}

The participants who obtained score more than 7 were considered perfect and who scored less than 7 were considered imperfect or not able to perform skills correctly Hand washing was performed by $93 \%$ participants, $67 \%$ were table to take proper temperature recording, $57 \%$ were able to weight newborns, $87 \%$ were able to apply eye ointment, $53 \%$ were able to cover the newborn with the blanket and $38 \%$ were able to keep the newborn in warm bag.

Table 3: Mean skill scores (out of max. score, MM: 60):

\begin{tabular}{|c|c|c|c|c|c|}
\hline S. No. & \multicolumn{3}{|c|}{ Place } & $\begin{array}{l}\text { Mean skills } \\
\text { score }\end{array}$ & $\begin{array}{c}\text { Std } \\
\text { deviation }\end{array}$ \\
\hline 1 & \multicolumn{3}{|c|}{ Indore division } & 46.82 & 8.5 \\
\hline 2 & \multicolumn{3}{|c|}{ Ujjain division } & 45.10 & 7.2 \\
\hline 3 & \multicolumn{3}{|l|}{ Total } & 45.96 & 7.90 \\
\hline \multicolumn{2}{|c|}{ Indore Division } & \multicolumn{2}{|c|}{ Ujjain Division } & Unpaired ' $\mathrm{t}$ ' test & P value \\
\hline Mean & SD & Mean & SD & value & \\
\hline 46.82 & 8.50 & 45.1 & 7.20 & 1.54 & 0.124 \\
\hline
\end{tabular}

Mean skill score of Indore and Ujjain Divisions came to be nearly equal and had no significant difference (Unpaired $\mathrm{t}$ test, $\mathrm{p}>0.05$ ).

There was significant change in performing activities Like Registration of pregnant mother, Accompany pregnant mother to hospital, Counselling on ANC, PNC, safe delivery, but minimal or no change in Distribution of IFA, Oral pills, ORS, Inform AWW/ANM on birth and death and Help ANM for immunization as ASHAs were already competent in these activities.

Also there was no change in Weighing of children below five years of age- assessing grades of malnutrition and Help AWW in supplementary nutrition feeding as they were not undertaking these activities even after undergoing this training. Majority of the ASHA workers get monthly income between Rs. 600 - Rs. 1200 per month and nearly around 25 get more than Rs. 1200 per month as incentives.
Cheques are delivered to ASHA workers by BCM in majority of the cases, or by BMO / MO and all the incentive related queries are forwarded to $\mathrm{BCM}$ or $\mathrm{BMO} / \mathrm{MO}$.

Majority of the ASHA workers are having cooperative bank accounts in comparison to few nationalized and post office accounts. Most of the ASHA (89\%) did not have any experience of delay in getting incentives. $82 \%$ of ASHA were satisfied with their incentives but all demand for regular monthly salary for income security.

Average monthly income of ASHA was around Rs. 1350. The Janani Suraksha Yojna (JSY) was found to be major source of incentives to the ASHAs. Malaria, leprosy and tuberculosis had a minor contribution in their incentive.

\section{Discussion}

ASHAs are the front line health personnel available in the rural areas to solve health emergencies and health needs of the people. This study has been conducted to know the effect of training (presently skill based training, 6th \& 7th module) on ASHAs knowledge, skills and their work behaviour using Kirkpatrick model of training evaluation.

Currently second round of skill based training (6th and 7th module) is in process in most of the districts of Madhya Pradesh including Indore, Jhabua, Dewas and Neemuch. This is a five days residential training being organised only at district headquarter of each district by selected non Governmental organization for each district.

Evaluation of skills, change in behaviour and incentive appraisal Skills: ASHAs were taught six specific skills hand washing, recording body temperature of a child/ newborn, weighing new born, application of eye ointment, covering new born with the blanket and Keeping newborn in the warm bag. 
Hand washing was performed by $93 \%$ participants, $67 \%$ were table to take proper temperature recording, 57\% were able to weight newborns, $87 \%$ were able to apply eye ointment, $53 \%$ were able to cover the newborn with the blanket and $38 \%$ were able to keep the newborn in warm bag.

More than $80 \%$ of ASHAs were competent in hand washing, recording temperature and applying eye ointment. Apart from these evaluated skills ASHA must have good communication and counselling skills which we had included in our study. Mean skill score of Indore and Ujjain Divisions came to be nearly equal and had no significant difference (Unpaired t test, $\mathrm{p}>0.05$ ).

Behaviour changes (practices): activities for pregnancy and maternal care, new born care, child health and nutrition and coordination with ANMs and AWWs were assessed by interviewing ASHAs themselves and their supervisor ANM.

Many ASHAs started activities like counselling mother for ANC, PNC, new born care and breastfeeding (from $32 \%$ to $67 \%$ ASHAs), motivating couple for family planning (from $21 \%$ to $56 \%$ ASHAs), providing care for new born(from $16 \%$ to $48 \%$ ASHAs), eye and umbilical care of the newborn(from $19 \%$ to $46 \%$ ASHAs), taking weight and temperature(from $8 \%$ to $28 \%$ ASHAs), managing feeding problems (from $5 \%$ to $28 \%$ ASHAs), managing sick new born child, diarrhoea and dehydration(from $9 \%$ to $47 \%$ ASHAs ), pneumonia/ ARI(from $6 \%$ to $30 \%$ ASHAs), conducting village level meeting (from $11 \%$ to $35 \%$ ASHAs), and maintenance of records and registers(from $34 \%$ to $77 \%$ ASHAs), which they were not doing earlier.

The study by Kochukuttan S et al (2013) [4] also revealed that $99 \%$ of ASHAs were supporting institutional deliveries. The study by Srivastav S. R. et al (2012) [5] revealed that $100 \%$ of the ASHAs helped Auxiliary Nurse Midwives (ANMs) in mobilizing beneficiaries at immunization sites, while in a study conducted in Gujarat by Patel $\mathrm{T}$ et al (2011) [6] "Process evaluation of routine immunization in rural areas of Anand District of Gujarat" revealed that only $11.4 \%$ of the healthcare workers were working as mobilizers for immunization sessions. Also, in a study by Jain $\mathrm{N}$ et al (2008) [7] "Assessment of the functioning of ASHAs under NRHM in Uttar Pradesh" conducted in Uttar Pradesh, 59\% of the immunization activities were facilitated by ASHA workers.
In another study in 2008 by Swain S et al [8] it was seen that $92.5 \%$ ASHAs accompanied pregnant mothers to hospitals, $87.5 \%$ did distribution of iron and folic acid, $68.8 \%$ did registration of pregnant mothers, and $80 \%$ mobilised beneficiaries and helped ANM for immunization. There was a contradictory finding i.e. in his study only $8.8 \%$ ASHAs inform AWW/ANM about birth and death compared to $77 \%$ in our study.

Similarly none of the ASHAs in our study were weighing children under five years of age-for assessment of grades of malnutrition and Help AWW in supplementary nutrition feeding even after undergoing current training. It was similar to the findings in study by Haider $S$ et al (2008) [9] in Jharkhand, where only $5.7 \%$ of the study participants promoted community members to receive Integrated Child Development Services (ICDS) facilities from Anganwadi Centre,

Many ASHAs started activities like counselling mother for ANC, PNC, new born care and breastfeeding (from $32 \%$ to $67 \%$ ASHAs). In the study by Swain $\mathrm{S}$ et al [8] (2008) 83.8\% ASHAs were practicing this activity. Motivating couple for family planning: only $20 \%$ ASHAs were motivating couples for family planning but after training $53 \%$ ASHAs were performing this activity.

Before training less than 9\% ASHAs were able to manage sick new born child, but after training more than $47 \%$ of ASHAs were able to manage breast feeding problems identify the danger signs of pneumonia and make referral, and $30 \%$ were able to identify the signs of severe dehydration and able to prepare and demonstrate ORS use to caregivers/mothers.

Janet Brandling et al 2010 [10] in his evaluation of first aid training of line managers working in public sector also found that there was significant improvement in confidence among participants to deal with the issues pertaining to mental health after undergoing training. Foreman $P$ et al [11] "evaluation of education and training of staff in dementia care in acute setting" 2005 also found increased comfort and confidence after training, in dealing with the patients of cognitive impairment by participants.

Also being poor in newborn-care most ASHAs were weak in organising village level meeting. This had been seen by Bhatt $H$. et al [12] in Uttrakhand in 2012 in Uttarakhand where ASHAs have indicated that they are unable to motivate the community for 
Construction of toilets and were not able to organize meeting. After undergoing training at least 30\% were able to perform this activity.

Only $8 \%$, ASHAs were able to maintain their records and registers before undergoing training. After training $33 \%$ were able to take proper temperature recording, Garg PK et al [13] (2012) in his found that record keeping practices by ASHAs were satisfactory except birth and death registration records which were relatively deficient in their maintenance and completeness.

While Kansal $S$ et al [14] in his study found that only $23 \%$ of registers were complete, $40 \%$ were incomplete and $37 \%$ were blank. This indicates that ASHAs were poor in maintenance of records and registers. In our study, after undergoing training we found improvement in record and register maintenances, and $80 \%$ of ASHAs were competent in this activity.

Incentives Issues of ASHAs: ASHAs were getting incentives for different activities through cheques. Cash was not given to any ASHA for any activity. There was no delay in getting incentives except in $11 \%$ cases (ASHA). The delay was complained to either $\mathrm{BCM}$ or $\mathrm{BMO} / \mathrm{MO}$ of the concerned areas and the problem take too much time ( 1 month) to get solved.

The problem of delay was mainly to newly recruited ASHAs (90\% cases). Only $82 \%$ ASHAs were satisfied with their current incentives but all were demanding fixed salary equal to Aaganwadi sahayikas (ICDS). Average monthly income of ASHA was around Rs. 1350.

Delay in incentive was also observed in a study by Bhatnagar et al (2009) [15] that $46.11 \%$ ASHAs were had problem. All ASHAs had their bank account in cooperative banks and only $10 \%$ had their account in nationalized bank and $7 \%$ had a post office account too.

In study by Bajpayi $\mathrm{N}$ et al [3] $75 \%$ ASHAs had their own bank account. More than half, 53\% ASHAs earned about Rs.600-1200 in a month and 30\% got more than Rs. 1200 per month and rest were getting less than Rs. 600 per month. In the study by Roy $S$ et al [16] (2013), he outlined the problem of incentive for ASHAs as "ASHA has no fixed pay.

For each institutional delivery when she accompanies the case to the hospital during and after delivery, she gets Rs.600 as incentive at the end of the month.
However, if there are no cases of institutional delivery in a particular month then she receives only a fixed sum of Rs.350 per month". Only 82\% ASHAs were satisfied with their current incentives but all were demanding fixed salary equal to Aaganwadi sahayikas (ICDS).

Average monthly income of ASHA was around Rs. 1350.The amount is almost same as was found in study by Bajpayi $\mathrm{N}$ et al [3] (2010) where annual average income of ASHA in Rajasthan and Bihar were Rs. 11,562 and Rs. 14,220, respectively.

However in the same study Chhattisgarh has a relatively low average annual income (Rs. 5,414) because the average population handled by ASHA is considerably less (less than 500); and for the same reason, the average annual income of ASHA in UP (Rs.17,646) is higher because they on an average handle larger population (around 1500).

On assessing the major activities which contribute to ASHA income, cases for the institutional delivery were the major contributor (Rs. 650). Other activities contribute very little to the income of ASHAs for e.g., full immunization of child (Rs 150), organising VHND (Rs. 150), LTT (Rs.150), ANC checkups, and IFS supplementation (Rs 100) per case.

But most of these activities are time long processes so ASHAs were less interested in these activities. Similarly since many ASHAs were not aware of their all roles and responsibilities, they were neither doing it nor getting incentives for that.

None of the ASHAs got incentive for giving health education, counselling and community mobilization. They were also not aware of any incentive regarding home visits for new born care and examination of sick new born child. So they were least interested in these.

\section{Conclusions}

Quality of training had a positive effect on knowledge, skills and activities undertaken by ASHAs. Lack of facility at the training centres, teaching aids, techniques and effectiveness of trainers has affected knowledge, skills and activities. The knowledge also get affected by the trainees age, qualification, prior trainings, years of working experience and the effect of young baby of the trainee. The work done by ASHAs was mostly focused on incentives; they were giving priorities to activities with good incentives over other activities, 
Due to this the activities of importance like newborn care, urgent referral of children with severe illnesses, DOTS providing, treatment of leprosy cases, malaria slide preparation and treatment of cases get hampered.

\section{Reference}

01. What Works for Children in South Asia. Community Health Workers Working Paper. (C) The United Nations Children's Fund (UNICEF) Regional Office for South Asia. 2004. available at: [Article] [Crossref]

02. Government of India. National Rural Health Mission (2005-2012) Mission Document. New Delhi- Ministry of Health and Family Welfare. 2005. Available at: [Article] [Crossref]

03. Bajpai N, Ravindra $H$. "Improving the performance of accredited social health activists in India". Dholakia Working Paper No-1. May 2011.

[Crossref]

04. Kochukuttan S, Ravindran TKS, Krishnan S. Evaluating Birth Preparedness and Pregnancy Complications Readiness Knowledge and Skills of Accredited Social Health Activists in India. International Journal of $\mathrm{MCH}$ and AIDS. 2013;2(1)121-128.

[Crossref]

05. Shrivastava SR, Shrivastava PS. Evaluation of trained accredited social health activist (ASHA) workers regarding their knowledge and attitude and practice about child health. Rural and Remote Health. 2012;12(4)2099.

Available: [Article] [Crossref]

06. Patel T, Raval D, Pandit N. Process evaluation of routine immunization in rural areas of Anand District of Gujarat. Healthline. $2011 ; 2(1) 17$. [Crossref]

07. Jain N, Srivastava NK, Khan AM, Dhar N, Manon S, Adhish V, Nandan D. Assessment of functioning of ASHA under NRHM in Uttar Pradesh. Health and Population- Perspectives and Issues. 2008;31(2)132-140.

[Crossref]
08. Swain S, Swain P, Nair KS, Dhar N, Gupta S, Nandan D. A rapid appraisal of functioning of ASHA under NRHM in Orissa. Health and Population- Perspectives and Issues. 2008;31(2)73-79.

[Crossref]

09. Haider S, Adhish SV, Gupta S, Dhar N, Datta U, Menon $S$, et al. A rapid appraisal of SAHIYA (ASHA) in Jharkhand. Health and PopulationPerspectives and Issues. 2008;31(2)80-84.

[Crossref]

10. Brandling J, et al. "Evaluating Mental Health First Aid Training for Line Managers working in the public sector". Mental Health First Aid Training Evaluation. 2010. Available at: [Article] [Crossref]

11. Foreman P, Gardner I. 2005 Evaluation of Education and Training of Staff in Dementia Care and Management in Acute setting. Report for the Department of Human Services. 2005. Available at: [Article] [Crossref]

12. Hema B. A rapid appraisal of functioning of ASHA under NRHM in Uttarakhand, India. Cooperation \& Development Center. May 2012. Assessed through: [Article] [Crossref]

13. Garg PK, Bhardwaj A, Singh A, Ahluwalia SK. An Evaluation of ASHA Worker's Awareness and Practice of their Responsibilities in Rural Haryana. National J Community Med. 2013;4(1)76-80.

[Crossref]

14. Kansal S, Kumar S, Kumar A. Is educational level of ASHA matters for their effective functioning?- A cross- sectional study in eastern Uttar Pradesh. Indian Journal of Community Health. 2012;24(1)41-44.

[Crossref]

15. Bhatnagar R, Singh K, Bir T, Datta U, Raj S, Nandan D. An assessment of performance based incentive system for ASHA Sahyogini in Udaipur, Rajasthan. Indian J Public Health. 2009;53(3)166-70.

[Crossref]

16. Roy S, Sahu B. Can ASHA be the ray of hope for providing $\mathrm{MCH}$ services in Odisha, India?Exploring through a qualitative study. Journal of global health care Systems. 3(2)2013.

[Crossref] 